\title{
Motor neuron disease in a defined English population: estimates of incidence and mortality
}

\author{
G Dean, M Quigley, M Goldacre
}

\begin{abstract}
Linked statistics from hospital records and death certificates were used to study the incidence of and mortality from motor neuron disease in a defined English population. The incidence of motor neuron disease, measured as firstadmission rates for the disease, was studied from 1963 to 1985 and death certificates for the patients admitted to hospital were obtained to the end of 1990. The average annual first-admission rate for motor neuron disease was $2 \cdot 1 / 100000$ men $(95 \%$ confidence interval (CI) 1.9 to $2 \cdot 4)$ and $1 \cdot 7 / 100000$ women (95\% CI 1.5 to 1.9). First-admission rates increased with age and peaked in the age range 65-84 years. Motor neuron disease was recorded on the death certificate for $86 \%$ of patients who died while they had the disease and there was no appreciable change over time in the recording of motor neuron disease as the underlying cause of death. The admission and mortality data derive from different sources, hospital statistical abstracts and death certificates respectively, but trends over time in the two data sets were similar. There was an increase in mortality during the period covered by the study, as there has been in mortality from motor neuron disease nationally, and the increase in mortality in the Oxford region was accompanied by an increase in first-admission rates. It is concluded that the increase in mortality from motor neuron disease probably occurred as a result of an increase in the diagnosed incidence of the disease rather than changes in death certification practice.
\end{abstract}

$(\mp$ Neurol Neurosurg Psychiatry 1994;57:450-454)

The Medico-Social Research Board of Ireland, Dublin, Ireland G Dean

Unit of Health-Care Epidemiology, University of Oxford Old Road, Oxford, UK $M$ Quigley

$M$ Goldacre

Correspondence to: Dr G Dean,

PO Box 1851, Ballsbridge, Dublin, Ireland.

Received 5 March 1993 and in revised form 28 July 1993.

Accepted 30 July 1993 many countries, including England, the reported mortality from motor neuron disease is increasing. ${ }^{1-5}$

This investigation is based on the Oxford Record Linkage Study (ORLS) founded by Acheson in $1963 .^{6}$ The ORLS brings together statistical information about all hospital admissions and deaths in a defined population. ${ }^{7}$ It offers a unique opportunity to study the incidence of motor neuron disease in a defined English population at a time of change in death rates ascribed to the disease.

\section{Methods}

STUDY POPULATION

The ORLS is a systematic collection of abstracts of records of all hospital admissions and deaths organised in such a way that data relating to the same subject can be linked. From 1963-5 data collection was undertaken in one part of the Oxfordshire health district (population 350 000). In 1966 it expanded to cover the whole of two health districts, Oxfordshire and West Berkshire (population 850000 ), and from 1975 data collection covered six of the eight districts of the Oxford Regional Health Authority (population 1.9 million). Data were recorded on all patients admitted to hospital in the area covered by record linkage, but not on patients who were resident in the area and admitted to hospitals outside it. Death certificates were available for all residents of the area regardless of place of death. We identified abstracts of hospital admissions from 1963 to 1985 and these were linked with death certificates to the end of 1990 .

\section{CASE NOTE REVIEW}

Ethical approval to study patients' case notes was obtained from local ethics committees and from the clinicians responsible for the care of patients in the study, or their successors. Computerised abstracts in the ORLS were then used to identify the hospital records of all patients aged 25 years and over who had been admitted to any hospital in the study area with a diagnosis code in the range covering motor neuron disease (three digit codes 356,348 , and 335 in the seventh, eighth, and ninth revisions respectively of the International Classification of Diseases (ICD)). We excluded records of patients coded as Werdnig Hoffman disease or spinal muscular atrophy (335.0 and 335.1 in the ninth revision of the ICD).

One of us (GD) sought further information from case notes, including evidence 
supporting the diagnosis of motor neuron disease, to supplement the statistical data in the ORLS. The diagnosis of motor neuron disease accepted for this study was that specified in the notes by the attending doctors, corroborated as far as possible by retrospective case note review by GD, bearing in mind the diagnostic criteria decided by the World Federation of Neurology Subcommittee on motor neuron disease at its workshop at $\mathrm{El}$ Escorial, Spain. ${ }^{8}$ There was a problem with certain hospitals in the West Berkshire district where the policy is to destroy all hospital case notes eight years after a patient's death. Where this had happened (in $16 \%$ of all records sought) we studied all the four digit diagnoses and cause of death codes on the computerised abstracts for each patient and used this information to determine whether or not the patient was likely to have had motor neuron disease.

The records of the neurophysiology department, department of neurology, Radcliffe Infirmary, Oxford, provided information on all patients who had had EMG studies and in whom a diagnosis of motor neuron disease was considered likely. No EMGs were undertaken in private clinics in the Oxford region, though a small number were carried out in National Health Service hospitals in Northampton and Kettering.

Because some patients resident in the ORIS area may have been investigated for motor neuron disease at London hospitals, we obtained a printout of all patients diagnosed as having motor neuron disease (ICD $335 \cdot 2$ ) for a ten year period, 1976-85, from the hospital activity analysis of the four Thames Regional Health Authority areas. Place of residence was coded on the printout. We also examined the diagnostic index of patients diagnosed as having motor neuron disease at the National Hospital for Nervous Diseases, Queen Square and Maida Vale. Only three patients from the ORIS area were found in London, diagnosed as having motor neuron disease, who had not also at some time been admitted to hospital with the disease in the Oxford region.

The National Health Service Central Register, Southport traced records for all patients for whom a death certificate was not already available and provided us with copies of those death certificates we did not already have. In particular, these included certificates for non-residents treated in the area and for people resident in the area who had migrated out of it.

\section{CALCULATION OF INCIDENCE, PREVALENCE, AND MORTALITY}

Incidence was measured as each subject's first recorded hospital admission for motor neuron disease (that is, incidence of admission to hospital). The first-admission rate was calculated taking those with motor neuron disease resident and treated in the study area as the numerator and the resident population of the area as the denominator. Population based mortality rates were calculated from data on death certificates for all deaths in subjects resident at the time of death in the study area for whom motor neuron disease was mentioned at any position on the death certificate.

Prevalence was calculated by identifying records for patients with a hospital admission for motor neuron disease before 31 December 1985 who were alive on that day.

Trends in annual first-admission and mortality were calculated for the six districts covered by the ORLS between 1975 and 1985 and for the two districts covered from 1963 to 1985. All rates are based on the annual estimates of the population as it was at the appropriate times for the areas covered by the ORLS, derived from figures published by the Office of Population Censuses and Surveys (OPCS) from the national censuses. In comparing trends over time, the annual first-admission and mortality rates have been age-standardised by the direct method using the 1981 population estimates as the standard population. The statistical significance of trends was tested by calculating $\chi^{2}$ values for trend on the age-standardised rates. This was calculated using the data for each individual calendar year although, for brevity, the years are grouped in the tables.

\section{Results}

AGE-SEX SPECIFIC RATES, RESIDENTS OF SIX DISTRICTS, $1975-85$

In the six districts covered by data collection from 1975 to 1985,434 residents were admitted to hospital with a diagnosis of definite or probable motor neuron disease (241 men and 193 women). In the same 11 year period, 460 residents died with motor neuron disease mentioned in some position on their death certificate ( 258 men and 202 women).

One hundred and forty-three $(33 \%)$ of the 434 patients with motor neuron disease admitted to hospital from 1975 to 1985 had an EMG examination in the Oxford Regional Health Authority area which supported the diagnosis. Eighty-three (58\%) of the 143 of these EMGs took place while the patient was in hospital at the time when motor neuron disease was diagnosed and $111(78 \%)$ took place either during this hospital episode or in the 35 days before or after it. In other words, the first clinical diagnosis and its confirmation by investigation were generally close together in time.

First-admission rates and mortality were higher in men than women and increased markedly with age in both sexes (table 1). The highest age-specific rates were at ages 65-74 and 75-84 years. The average annual first-admission rate for motor neuron disease for people aged 25 and over, using the population of each sex aged 25 and over as the denominator, was $3 \cdot 6 / 100000$ men and $2 \cdot 7 / 100000$ women. The average annual mortality per 100000 population for those 25 years of age and over was 3.8 for men and 2.8 for women. Taking the all-ages population as the denominator, the average annual firstadmission rate per 100000 people of all ages 
Table 1 Average annual first-admission rates and mortality for motor neuron disease per 100000 population in each age-sex group in six districts, 1975-85 (and numbers in the 11 year period on which the rates are based):residents of the six districts only

\begin{tabular}{|c|c|c|c|c|c|c|}
\hline \multirow[b]{2}{*}{ Age-group (years) } & \multicolumn{3}{|c|}{ First admission } & \multicolumn{3}{|c|}{ Mortality } \\
\hline & No & (rate) & $(95 \% C I)$ & No & (rate) & $(95 \% C I)$ \\
\hline \multicolumn{7}{|l|}{ Men } \\
\hline $\begin{array}{l}25-34 \\
35-44 \\
45-54 \\
55-64 \\
65-74 \\
75-84 \\
85+ \\
\text { All ages* } \\
\text { All ages }\end{array}$ & $\begin{array}{r}4 \\
15 \\
28 \\
70 \\
72 \\
48 \\
4 \\
241 \\
241\end{array}$ & $\begin{array}{c}(0 \cdot 2) \\
(1 \cdot 0) \\
(2 \cdot 2) \\
(6 \cdot 3) \\
(9 \cdot 2) \\
(15 \cdot 1) \\
(7 \cdot 6) \\
(3 \cdot 6) \\
(2 \cdot 1)\end{array}$ & $\begin{array}{l}(0.0 \text { to } 0.5) \\
(0.5 \text { to } 1.5) \\
(1.4 \text { to } 3.0) \\
(4.8 \text { to } 7.8) \\
(7.0 \text { to } 11.3) \\
(10.8 \text { to } 19.4) \\
(0.2 \text { to } 15.2) \\
(3.1 \text { to } 4.0) \\
(1.9 \text { to } 2.4)\end{array}$ & $\begin{array}{r}2 \\
8 \\
23 \\
52 \\
103 \\
63 \\
7 \\
258 \\
258\end{array}$ & $\begin{array}{l}(0 \cdot 1) \\
(0.5) \\
(1 \cdot 8) \\
(4 \cdot 7) \\
(13 \cdot 1) \\
(19 \cdot 8) \\
(13 \cdot 3) \\
(3 \cdot 8) \\
(2 \cdot 3)\end{array}$ & $\begin{array}{l}(0.0 \text { to } 0.3) \\
(0.2 \text { to } 0.9) \\
(1.1 \text { to } 2.5) \\
(3.3 \text { to } 5.9) \\
(10.6 \text { to } 15.6) \\
(14.9 \text { to } 24 \cdot 7) \\
(3.5 \text { to } 23.2) \\
(3.4 \text { to } 4.3) \\
(2.0 \text { to } 2.6)\end{array}$ \\
\hline \multicolumn{7}{|l|}{ Women } \\
\hline $\begin{array}{l}25-34 \\
35-44 \\
45-54 \\
55-64 \\
65-74 \\
75-84 \\
85+ \\
\text { All ages* } \\
\text { All agest }\end{array}$ & $\begin{array}{r}3 \\
5 \\
19 \\
51 \\
71 \\
36 \\
8 \\
193 \\
193\end{array}$ & $\begin{array}{l}(0 \cdot 2) \\
(0 \cdot 3) \\
(1 \cdot 5) \\
(4 \cdot 4) \\
(7 \cdot 4) \\
(6 \cdot 3) \\
(4 \cdot 8) \\
(2 \cdot 7) \\
(1 \cdot 7)\end{array}$ & $\begin{array}{l}(0.0 \text { to } 0.4) \\
(0.0 \text { to } 0.6) \\
(0.8 \text { to } 2.2) \\
(3.2 \text { to } 5.6) \\
(5.7 \text { to } 9.2) \\
(4.3 \text { to } 8.4) \\
(1.5 \text { to } 8.2) \\
(2.3 \text { to } 3.1) \\
(1.5 \text { to } 1.9)\end{array}$ & $\begin{array}{r}3 \\
2 \\
14 \\
46 \\
72 \\
52 \\
13 \\
202 \\
202\end{array}$ & $\begin{array}{l}(0 \cdot 2) \\
(0 \cdot 2) \\
(1 \cdot 1) \\
(4 \cdot 0) \\
(7 \cdot 5) \\
(9 \cdot 1) \\
(7 \cdot 9) \\
(2 \cdot 8) \\
(1 \cdot 8)\end{array}$ & $\begin{array}{l}(0.0 \text { to } 0.4) \\
(0.1 \text { to } 0.3) \\
(0.5 \text { to } 1.7) \\
(2.8 \text { to } 5.1) \\
(5.8 \text { to } 9.3) \\
(6.6 \text { to } 11.6) \\
(3.6 \text { to } 15.2) \\
(2.4 \text { to } 3.2) \\
(1.5 \text { to } 2.0)\end{array}$ \\
\hline
\end{tabular}

$\mathrm{CI}=$ Confidence interval.

*All people aged 25 years and over per 100000 population aged 25 years and over.

tAll people aged 25 years and over per 100000 population of all ages.

was $2 \cdot 1$ for men and $1 \cdot 7$ for women. The average annual mortality per 100000 people of all ages was 2.3 for men and 1.8 for women (table 1). Age-specific mortality in Oxford was similar to that in the same period in England as a whole for people under 65 years of age. In older people it was a little higher in Oxford than in England.

There was no important change over time in the proportion of deaths from motor neuron disease which were recorded as the underlying cause of death on the death certificates. For example, in the period covered by the seventh and eighth revisions of the ICD, 1963-78, it was the underlying cause of death in $168 / 225(75 \%)$ subjects, and in $1979-85$ it was the underlying cause in $205 / 275$ (75\%). Motor neuron disease was recorded at any position on the death certificate in $187 / 225$ (83\%) subjects in $1963-78$ and in $241 / 275$ (88\%) subjects in $1979-85$.

Some subjects with motor neuron disease on the death certificate had no record of previous hospital admission for motor neuron disease in the ORLS area. In general, in our study design it would not be possible to identify admissions which were in fact for motor neuron disease when the diagnosis was not recorded as such. Forty one subjects with motor neuron disease on the death certificate died in hospital $(9 \%$ of all deaths in the study) without motor neuron disease on the hospital record. Of these 41 , seven (17\%) had no coded hospital diagnoses, 23 (56\%) had various specific codes for acute respiratory or cardiovascular events (probably their terminal events), seven ( $17 \%$ ) had codes for neurological disorders other than motor neuron disease, and four (10\%) had other codes.

\section{TRENDS IN AGE-SEX SPECIFIC INCIDENCE AND MORTALITY}

Table 2 gives the trends over time in average annual first recorded hospital admission rates for motor neuron disease. First-admission rates and mortality increased for men and women during part of the period covered by the study. When mortality increased, there had also been an increase in first-admission rates (table 2). The increase for men occurred particularly in the two districts from the early to mid-period of the study whereas that for women increased in the six districts in the later period. National death rates showed a slightly earlier increase for men than women.

\section{SURVIVAL AND PREVALENCE}

Survival times decreased as age increased, from a median of over 1000 days for subjects less than 45 years of age to under 200 days for people aged 75 years or older. Men survived longer (median 497 days) than women (median 351 days). These survival times mean that, on average, most subjects who contribute to the incidence figures in one year (table 2) will have appeared in the mortality figures about one year later.

The prevalence of a disease is proportional to its annual incidence and duration. For a disease with a mean survival of about one year, annual incidence, mortality, and prevalence will have about the same numerical value. We calculated prevalence on the last day for which we sought hospital data, 31 December 1985, by estimating numbers of subjects resident in the six districts with motor neuron disease who were alive on that date. There were 58 men and 27 women

Table 2 Trends in average annual first-admission rates and average annual mortality for motor neuron disease per 100000 population, $1963-85$. Values are no (rate/100000)

\begin{tabular}{|c|c|c|c|c|c|c|c|c|}
\hline \multirow[b]{3}{*}{ Years } & \multicolumn{4}{|l|}{ Men } & \multicolumn{4}{|l|}{ Women } \\
\hline & \multicolumn{2}{|c|}{ Two districts } & \multicolumn{2}{|l|}{ Six districts } & \multicolumn{2}{|c|}{ Two districts } & \multicolumn{2}{|l|}{ Six districts } \\
\hline & Admission & Mortality & Admission & Mortality & Admission & Mortality & Admission & Mortality \\
\hline $\begin{array}{l}1963-5^{\star} \\
1966-8 \\
1969-71 \\
1972-4 \\
1975-7 \\
1978-80 \\
1981-3 \\
1984-5 \\
\chi^{2} \dagger\end{array}$ & $\begin{array}{c}11(4 \cdot 0) \\
30(4 \cdot 6) \\
24(3 \cdot 5) \\
21(2 \cdot 8) \\
24(3 \cdot 1) \\
31(3 \cdot 9) \\
38(4 \cdot 6) \\
22(3 \cdot 6) \\
3 \cdot 6\end{array}$ & $\begin{array}{c}6(2 \cdot 3) \\
24(3 \cdot 7) \\
19(2 \cdot 8) \\
30(4 \cdot 0) \\
24(3 \cdot 0) \\
24(3 \cdot 0) \\
40(4 \cdot 8) \\
24(3 \cdot 9) \\
1 \cdot 2\end{array}$ & $\begin{array}{l}\overline{ } \\
\bar{Z} \\
\overline{4} \\
48(2 \cdot 7) \\
62(3 \cdot 4) \\
86(4 \cdot 5) \\
45(3 \cdot 4) \\
5 \cdot 3 \ddagger\end{array}$ & $\begin{array}{l}- \\
\bar{Z} \\
\overline{-} \\
45(2 \cdot 6) \\
71(3 \cdot 9) \\
85(4 \cdot 4) \\
57(4 \cdot 2) \\
9 \cdot 3 \ddagger\end{array}$ & $\begin{array}{r}6(1 \cdot 7) \\
16(2 \cdot 2) \\
11(1.5) \\
15(1.9) \\
19(2 \cdot 3) \\
32(3 \cdot 8) \\
25(2 \cdot 8) \\
22(3.5) \\
8 \cdot 2 \ddagger\end{array}$ & $\begin{array}{r}7(2 \cdot 2) \\
16(2 \cdot 2) \\
17(2 \cdot 3) \\
13(1 \cdot 7) \\
22(2 \cdot 6) \\
36(4 \cdot 2) \\
24(2 \cdot 7) \\
26(4 \cdot 1) \\
7 \cdot 9 \ddagger\end{array}$ & $\begin{array}{l}\overline{ } \\
\bar{Z} \\
\overline{46}(2 \cdot 4) \\
64(3 \cdot 3) \\
43(2 \cdot 1) \\
40(2 \cdot 9) \\
0.0\end{array}$ & $\begin{array}{l}= \\
= \\
41(2 \cdot 2) \\
66(3 \cdot 4) \\
52(2 \cdot 6) \\
44(3 \cdot 1) \\
1 \cdot 4\end{array}$ \\
\hline
\end{tabular}

*Population covered less than in subsequent years.

tChi-squared values for trend, $1 \mathrm{DF}$, calculated on data for each individual calendar year in each column. $\mp \mathrm{p}<0.05$. 
alive in the 1.9 million population. This gave prevalences of $5 \cdot 4 / 100000$ men $(95 \%$ confidence interval (CI) 4.0 to 6.8 ) and $2 \cdot 5 / 100000$ women (95\% CI 1.6 to $3 \cdot 4$ ). These are consistent with what would be expected from the incidence and mortality in table 1, which are themselves similar, and from the slightly longer survival times in some men than women.

\section{Discussion}

First-admission rates and mortality for motor neuron disease increased with age for both sexes, with a peak in the seventh decade of life and a decrease in the very old. This decrease may be an artefact because the symptoms of motor neuron disease may not be so easily diagnosed in those in their eighties and nineties and, when it does occur, the very old are more likely to die from complications, such as pneumonia, before they are fully investigated for motor neuron disease.

The average annual first-admission rates, annual mortality, and point prevalences were similar for the all-ages data, though these relations varied a little within the age-specific rates because of longer survival times in the young than the old. The true prevalence of motor neuron disease could be considered by including the time from the first symptom likely to have been due to motor neuron disease to a definite diagnosis, as well as the time from diagnosis to death. A subsequent paper will discuss the time interval between the first symptom remembered by the patient, and quoted on the patient's hospital records, and the diagnosis.

Siddique et al have shown that in familial mendelian dominant motor neuron disease the gene responsible in older people is linked to chromosome $21 .{ }^{9} \mathrm{~A}$ different gene, perhaps linked to chromosome 2, may cause familial motor neuron disease in some young people. It has been stated that motor neuron disease occurs in two or more members of a family in about $10 \%$ of all patients. In our study there were only three families found with two or more members affected. We believe that familial motor neuron disease was underascertained due to inadequate recording of family history in the patient's records.

There was an increase in mortality for motor neuron disease nationally and in the Oxford region between 1963 and 1985. The first-admission rates for motor neuron disease, though best available estimates, undoubtedly slightly underestimate the incidence of motor neuron disease. This is because some people will have been admitted before the time period covered by the study, outside the area covered by it, or, as discussed earlier, may have had an admission without motor neuron disease on the hospital record abstract. We do not know whether there have been changes over time in the percentage of patients with motor neuron disease who were missed in these ways, but the general similarity in trends, comparing the first-admission rates and mortality, suggest that any such change is probably not large. The increase in first-admission rates and mortality over time occurred in all age groups but particularly in older age groups. Neilson et al have suggested that the increase in mortality from motor neuron disease might be due to the increased survival of a cohort of people liable to develop motor neuron disease who would previously have died of other competing disorders. ${ }^{10}$ This is a difficult hypothesis to test but it is not likely to have caused the increase in mortality from motor neuron disease across several age groups in such a relatively short period of time. Indeed, the fact that the increase, though most marked in the elderly, has been seen across a wide age range, both in the Oxford data and in English national mortality statistics, is more indicative of a period than a cohort effect. It has been suggested that the increase in mortality from motor neuron disease may be due to improved neurological services and, in the USA but not in England and Wales, to the increase that has occurred in the number of neurologists. ${ }^{5}$ This is not likely to be the cause of the increase in the Oxford region as the region has had an excellent neurological service, with only a small increase in the number of neurologists, since the start of the ORLS. The possibility remains that increasing awareness of the disease among general practitioners and general physicians might have led to increased referral and more accurate diagnosis.

Although our data are linked, the sources of our data on the first-admission rates and mortality are different. The former derive from routine abstracts of hospital admission records whereas the latter are from death certificates. Thus case ascertainment by us of incident cases was generally independent of, and therefore unbiased by, the trends in mortality. There were also no important changes over time in the extent to which motor neuron disease was recorded on the death certificates for people known to have had the disease. For these reasons we conclude that the increase in mortality, at least in the Oxford region, reflected an increase in the diagnosed incidence of motor neuron disease.

The Unit of Health-Care Epidemiology and the Oxford Record Linkage Study are funded by the Department of Health and the Oxford Regional Health Authority. We thank Prolth and Professor John Newsom-Davies, professor of neurology in the Oxfor Regional Health Authority area; Dr George Cochrane and D John Outhwaite of Mary Marlborough Lodge Rehabilitation Centre, Oxford, all of whom gave us access to their hospital records; Dr Geoffrey Rushworth, Dr Kerry Mills and their assistant, Mrs Anita Davis, the department of neurophysiology, the Radcliffe Infirmary, Oxford, Dr Clare Whitehead and
Dr Nigel Hyman, the Royal Berkshire Hospital, Reading, and Dr Ian Morris, Northampton and Kettering General Hospitals, provided access to their EMG reports. We also thank the personnel officers and record staff in the hospitals in the region and Ms Jackie Mills, personnel officer at the National Hospital for Neurology, Queen Square and Maid Vale. The four Thames Regional Health Authorities provided computer printouts of patients resident in the Oxford region diagnosed as having motor neuron disease and admitted to hospital in London. The Office of Population Censuses and Surveys provided mortality statistics and the National Health Service Central Register, Southport, traced missing death certificates. The study was undertaken with the assistance of a thicates. The study was undertaken with the assistance of a Britain and Northern Ireland. 
1 Buckley J, Warlow C, Smith P, Hilton-Jones D, Irvine S, Tew JR. Motor neuron disease in England and Wales, 1959-1979. I Neurol Neurosurg Psychiatry 1983;46: 197-205.

2 Lilienfeld DE, Ehland J, Landrigan PJ, et al. Rising mortality from motoneuron disease in the USA 1962-84. Lancet 1989; i:710-3.

3 Durleman S, Alperovitch A. Increasing trend of ALS in France and elsewhere: are the changes real? Neurology 1989;39:768-73.

4 Flaten TP. Rising mortality from motoneuron disease. Lancet 1989;i:1018-9.

5 Elian M, Dean G. The changing pattern of motor neuron disease and multiple sclerosis in England and Wales and the Republic of Ireland. Neurophysiology 1992;11: the Reput

6 Acheson ED. Medical record linkage. Oxford: Oxford
University Press, 1967

7 Gill LE, Baldwin JA. Methods and technology of record linkage: some practical considerations. In: Baldwin JA, Acheson ED, Graham WJ, eds. Textbook of medical record linkage. Oxford: Oxford University Press, 1987: 39-54.

8 Swash M, Leigh N. Workshop report. Neuromusc Dis 1992;2:7-9.

9 Siddique $\mathrm{T}$, et al. Linkage of a gene causing familial amyotrophic lateral sclerosis to chromosome 21 and evidence of genetic-locus heterogeneity. $N$ Engl $f \mathrm{Med}$ 1991;324:1381-4.

10 Neilson S, Robinson I, Hunter M. Longitudinal gompertzian analysis of ALS mortality in England and Wales, 1963-1989: estimates of susceptibility in the general population. Mech Ageing Dev 1992;64: 201-16.

\section{NEUROLOGY IN LITERATURE}

\section{Neurosyphilis}

Considering the number of syphilitic writers, descriptions of neurosyphilis in the literature are fairly uncommon. As yet I have not encountered a convincing description of meningovascular syphilis other than Mann's pathological essay, but thought the description in Mother Courage of secondary syphilis sufficiently charming to merit its inclusion. Kipling is said to have consulted with Ernest Gowers in order to write his description of tabes dorsalis. Thomas Mann is one of the few authors to have described the gradual development of disability in the syphilitic individual. The same book also contains a horrifying description of the terminal stages of untreated meningitis.

Fohann von Grimmelshausen, 1669, Mother Courage At the very moment when the earth was adorning itself with its robe of many-coloured flowers my skin erupted in pretty pustules, red as rubies, to grace my fair complexion - the rubies vanished in due course, but my doctor warned me that my blood was still not fully cleansed and advised me to continue my cure at the town of Griesbach with the help of mineral waters, in order to achieve a perfect recovery and be completely restored.

Rudyard Kipling in Many inventions, 1893, Love-o'Women

“"' 'Tention', sez the docthor; an' Love-o'-Women stud so. 'Now shut your eyes', sez the docthor. 'No, ye must not hould by your comrade.' ' 'Tis all up,' sez Love-o'-Women, thrying to smile. 'I'd fall, docthor, an' you know ut.' ...'But fwhat ails him, docthor?' I sez. 'They call ut Locomotus Attacks-us,' he sez, 'bekaze,' sez he, 'ut attacks us like a locomotive, if ye know fwhat that manes. An' ut comes,' sez he, lookin' at me, 'ut comes from bein' called Love-o'-Women.' ...'You're jokin', docthor,' I sez ...'Jokin'!' sez he. 'If iver you feel that you've got a felt sole in your boot instid av a Governmint bull's-wool, come to me,' he sez, 'an I'll show you whether 'tis a joke."'

Marcel Proust, vol 2, translated by CK Scott Moncrieff and Terence Kilmartin, 1920, 1921, 1922, Rememberance of things past

But on hearing $\mathbf{M}$ de Charlus say, in that shrill voice and with that smile and those gestures, "No, I preferred its neighbour, the strawberry-juice," One could say: "Ah, he likes the stronger sex," with the same certainty as enables a judge to sentence a criminal who has not confessed, or a doctor a patient suffering from general paralysis who himself is perhaps unaware of his malady but has made some mistake in pronounciation from which it can be deemed that he will be dead in three years.

Fames foyce, 1922, Ulysses

That fellow I was with in the Ship last night said Buck Mulligan, says you have g.p.i. He's up in Dottyville with Conolly Norman. General paralysis of the insane.

Thomas Mann, 1947, Doctor Faustus

But I mean these flagellates, the invisible tiny ones, the kind that have scourges, like on pale Venus, the spirochaeta pallida, that is the true sort.... To be short, the meta-spirochaetose, that is the meningeal process, and $I$ assure you, it is just as though certain of the little ones had a passion for the upper storey, a special preference for the head region, the meninges, the dura mater, the tentorium, and the pia, which protect the tender parenchyma inside and from the moment of the first general contagion swarmed passionately hither....You have there the spinal sac with the pulsating column of fluid therein, reaching to the cerebrum, to the meninges, in whose tissues the furtive venereal menigitis is at its soundless stealthy work....That might perhaps alarm me, the more because there was about the widened gaze a fixity-or shall I say it was a stare? - the nature of which I puzzled over until it occurred to me that it depended on the unvarying size of the not quite round, rather irregularly lengthened pupils, as though they remained unaffected by any alteration in the lighting. ...Only certes I should suffer the knives of pain therefore, even in the time, as the little sea-maid suffered them in her legs, which was my sister and sweet bride, and named Hyphialta. ...Reverence forbids me to describe Adrian's condition when he came to himself after the twelve hours' unconsciousness with which the paralytic stroke at the piano had plunged him. No, not to himself did he come; rather he found himself as a stranger, who was only the burnt-out husk of his personality, having at bottom nothing to do with him who had been called Adrian Leverkuhn. After all, the word "dementia", originally meant nothing else than the aberration from self, self-alienation.

G D PERKIN

Regional Neurasciences Centre, Charing Cross Hospital, London W6 8RF, UK 